\title{
Research Article \\ Steelmaking-Casting of Molten Steel by Decarburization Ladle Matching
}

\author{
Wei Liu $\left(\mathbb{D},{ }^{1}\right.$ Xinfu Pang $\mathbb{D}^{2},{ }^{2}$ Shengping Yu, ${ }^{1}$ Congxin $\mathrm{Li}^{3}{ }^{3}$ and Tianyou Chai ${ }^{1}$ \\ ${ }^{1}$ State Key Laboratory of Synthetical Automation for Process Industries, Northeastern University, Shenyang, Liaoning 110819, China \\ ${ }^{2}$ School of Automation, Shenyang Institute of Engineering, Shenyang, Liaoning 110136, China \\ ${ }^{3}$ Information \& Control Engineering Faculty, Shenyang Jianzhu University, Shenyang, Liaoning 110168, China
}

Correspondence should be addressed to Wei Liu; liuwei_cn@foxmail.com

Received 26 November 2017; Accepted 12 March 2018; Published 22 April 2018

Academic Editor: Simone Bianco

Copyright (C) 2018 Wei Liu et al. This is an open access article distributed under the Creative Commons Attribution License, which permits unrestricted use, distribution, and reproduction in any medium, provided the original work is properly cited.

\begin{abstract}
Steelmaking-continuous casting is a complex process. The method of selecting a ladle, which also functions as a storage device, follows a specific process of the production plan. In ladle matching, several ladle attributes are considered. However, matching objectives are difficult to achieve simultaneously. Different molten steel properties have contributed to the complexity of matching constraints, and, thus, matching optimization is regarded a multiconflict goal problem. In the process of optimization, the first-order rule learning method is first used to extract key ladle attributes (performance indicators), including highest temperature, usage frequency, lowest-level material, and outlet. On the basis of a number of indicators, such as ladle temperature, quantity, material, and usage frequency, as well as skateboard quantity, the ladle matching model is established. Second, the rule of ladle selection is determined by the method of least-generalization rule learning. Third, a simulation experiment is carried out according to various scheduling order strategies and matching priority combinations. Finally, the heuristic ladle matching method based on the rule priority (RP) is determined for possible industrial applications. Results show that the accuracy of ladle selection can be improved. In particular, the numbers of ladles and maintenance times are reduced. Consequently, furnace production efficiency is also enhanced.
\end{abstract}

\section{Introduction}

Modern steelworks involve the three production stages: steelmaking, refining, and continuous casting. In steelmakingcontinuous casting, a ladle corresponds to the furnace (smelting molten steel converter) used in container production. The process of ladle matching affects steel composition and processing temperature, which in turn affect the processing time of the furnace. Towards process completion, the furnace is also regarded as refining equipment used to improve product quality. Therefore, steelmaking-continuous casting and ladle matching are collectively a multiobjective conflict problem, especially if site selection for the ladle is conducted manually and the degree of process optimization is very low.

Paper [1] proposed a hybrid fruit fly optimization algorithm for the realistic hybrid flowshop rescheduling problem in steelmaking systems. Paper [2] studied ladle interlacing conditions and factors and their effect on multiple continuous casting machines in steel mills. Paper [3] introduced a computerized scheduling model for continuous casting in steel plants. Paper [4] established an integrated system for steel ladle scheduling. Paper [5] analyzed the impact of ladles on steelmaking scheduling. In these studies, ladle matching is analyzed in the context of basic property constraints for simplified production, but the complicated properties of ladles (temperature, material, number of uses, etc.) are not considered. Thus, optional ladle optimization is low, a condition that hardly meets steelmaking-continuous casting production requirements.

Paper [6] used the Gantt chart to analyze the rules of ladle turnover and construct the model for ladle turnover rate control. Paper [7] studied the static basic oxygen furnace endpoint control model to minimize the use of ladle furnaces during steelmaking. Paper [8] proposed a ladle schedule based on a production plan and ladle waiting time analysis. Paper [6] constructed a ladle turn number control model, whereas Paper [9] focused on ladle operation to reasonably calculate ladle quantity. Paper [10] studied an improved 
teaching-learning-based optimization algorithm for solving chiller loading optimization problems. Paper [11] attributed the issue of ladle scheduling to the problem of vehicle routing with time window and vehicle adjustment time. Based on service molten steel constraints, a mathematic model for ladle scheduling was established. Then, based on model characteristics, a distributed search method was proposed and a simulation experiment was conducted. Paper [12] summarized the issue of ladle scheduling as a problem of vehicle routing with time window and higher-level constraints, then a mathematical model was established to solve specific problems. In these studies, the main focus was on ladle management, including ladle turnover, simplified constraints for ladle selection, and simplified ladle production modeling. However, complex constraints related to ladle matching were not considered. Consequently, the optimal matching ladle requirement for actual production could not be achieved.

Taking a large iron and steel enterprise in Shanghai as an example, the influencing factors of ladle selection in steelmaking-continuous casting were analyzed. Data on field ladle selection were collected, and then the first-order rule learning method was used to extract the optimization target and establish the ladle matching model. On the basis of leastgeneralization rule learning, the rules for ladle selection were extracted and the RP-based heuristic ladle selection method was studied for different scheduling order method strategies and matching priority groups. The influence of scheduling strategy and matching priority on the result is analyzed, and the best result is selected for industrial application verification.

\section{Problem Description: Ladle Option Treatment}

Modern large-scale steelmaking-continuous casting consists of multiple converters, refining furnaces, and casters that are used for different refining methods. The converter smelts molten steel for ladle treatment, from which a ladle drives molten steel to one or more furnaces for refining (i.e., singleor multirefining furnace). After refining, the same ladle is used to drive molten steel to a casting machine rotary table for Tundish injection, and this process is known as pouring (i.e., continuous casting in the same casting furnace set). After the molten steel in the ladle is fully injected, the ladle goes offline to complete the shipping process. Figure 1 shows the dispatch schedule of a large Chinese iron and steel enterprise.

Current methods of ladle treatment plans are conducted manually in factories. The converter, refining equipment, and continuous casting machine in the production process are fixed whereas ladles, which serve as a refractory (i.e., made of steel carrying containers) to transport molten steel, are nonfixed. Ladles are therefore subjected to heat transfer during production. However, beyond molten steel transport, ladles are essentially an integral part of the refining process, which implies that steelmaking-continuous casting operation cannot be accomplished without ladle treatment.

Ladle-to-converter treatment handles molten steel depending on steel type requirements. Some ladles are

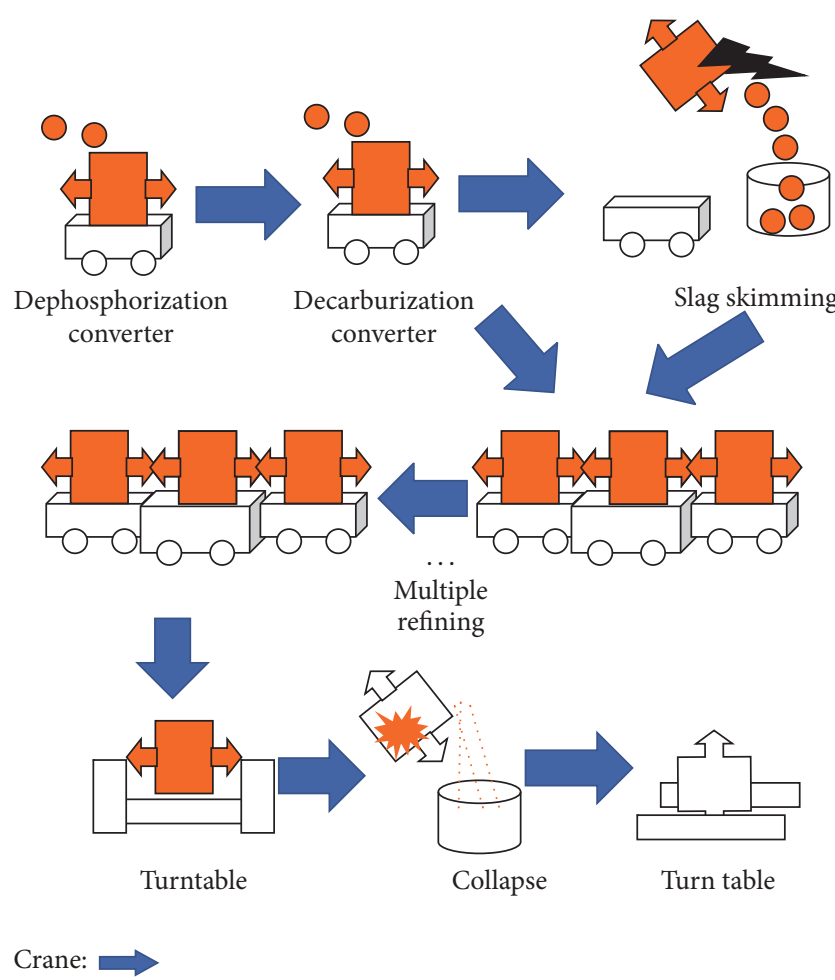

FIGURE 1: Steelmaking-continuous casting scheduling.

automatically directed to the slagging station whereas other ladles skip the slashing station. Some ladles are also directly linked to refining machines. Ladles are used to direct large containers of molten steel to a turntable station for casting after heavy-, double-, triple-, or quadruple-method refining. Then, the ladles move to specific slag pouring stations to empty the molten steel containers to a tilt table. Ladle inspection involves the process of alternate pouring of containers for package walking and empty bag walking. Empty bag walking entails less stringent time requirements and lower production impact compared with repackaging during actual production. Converter smelting involves the two stages of dephosphorization and decarburization in double-method steelmaking. When the furnace does not require dephosphorization, the direct-matching decarburization ladle is used; otherwise, the dephosphorization ladle followed by the decarburization ladle is considered.

Decarburization ladle treatment affects furnace temperature and composition directly and furnace processing time indirectly, or essentially the entire production equipment schedule to avoid schedule disruption. The influences can be further described as follows: (1) Ladle quality directly affects refining process time. If ladle material does not meet steel grade requirements, then the material affects molten steel quality. Subsequently, the refining time or refining process needs to be increased or enhanced, but these conditions may result in increased steel scrapping. (2) If the molten steel furnace is directed to the converter after smelting, then ladle treatment is skipped to avoid extending converter processing time. (3) If optional ladle treatment does not 
meet temperature requirements, then the processing time of the furnace in the refining equipment is extended to supplement temperature loss as a result of ladle temperature transfer to the molten steel. Ladle heating time on the baking equipment is increased when ladle temperature is too low, but this condition increases energy consumption and delays plan scheduling.

Ladle insulation material $M_{1}$ determines the temperature drop per unit of ladle treatment. The following influencing factors are considered: the greater the number of uses $L$, the less effective the insulation performance; the higher the initial temperature of the ladle $T_{1}$, the higher the temperature of molten steel during continuous caster pouring; and the higher the outside temperature $T_{2}$, the lower the temperature drop per unit of time during ladle treatment.

The ladle under nozzle material $M_{2}$ conducts thermal conductivity to a certain extent, but this condition impacts ladle heat, thereby causing a temperature drop of molten steel. Moreover, drainage agent materials affect automatic ladle pouring rate. As the automatic pouring rate of steel water temperature decreases, the remaining molten steel $R$ affects the composition of current heat.

Ladle matching considers the following factors:

(1) The decrease in temperature of the molten steel affects the quality of the final molten steel, and this condition is expressed as

$$
T_{0}=F\left(M_{1}, L, T_{1}, T_{2}, M_{2}, M_{3}, d\right),
$$

where $F(\bullet)$ is an unknown nonlinear relationship between molten steel temperature $T_{0}$ and its influencing factors, while $d$ is an unknown influencing factor.

(2) The ladle itself is on the molten steel is expressed as

$$
C=F\left(M_{1}, L, T_{1}, R, D, M_{2}, M_{3}, d\right),
$$

where $F(\bullet)$ is an unknown nonlinear relationship between molten steel composition $C$ and its influencing factors, while $d$ is an unknown influencing factor.

(3) Molten steel ladle refractory corrosion is expressed as

$$
E=F\left(M_{1}, L, T_{1}, C, t, d\right),
$$

where $F(\bullet)$ is an unknown nonlinear relationship between the degree of corrosion of decarbonization ladle refractory $E$ and its influencing factors.

\section{Ladle Matching Model}

\subsection{Symbols and Parameter Definitions}

$k$ : Ladle serial number

$i$ : Pour order number

$j$ : Furnace sequence number

$L_{i j}: i$ th casting sequence of the $j$ th heats

$T(k)$ : $j$ th heats of casting sequence $i$ being matched with the temperature of ladle $k$

$L_{\text {min }}$ : Minimum number of optional ladle requirements
$L_{\max }:$ Maximum number of optional ladle requirements

$M_{\text {min }}$ : Minimum furnace optional ladle material requirements

$M_{\max }$ : Maximum furnace optional ladle material requirements

$D(k)$ : Ladle number of openings

$D_{\text {min }}$ : Minimum number of optional ladle furnace requirements

$D_{\text {max }}$ : Furnace times the maximum number of optional ladles

$U(k)$ : Number of ladles

$U_{\text {min }}$ : Furnace times the minimum number of water ladle requirements

$U_{\max }$ : Furnace times the maximum number of usage of ladle water requirements

$S k_{a b}$ : Grade steel value

$\Omega$ : Available ladle collection.

3.2. Optional Ladle Decision Variables. Ladle matching needs to meet furnace requirements in accordance with the defined process and the as-far-as-possible ladle matching properties.

$$
x_{i j}^{k}= \begin{cases}1, & \text { If the furnace } L_{i j} \text { selected ladle } k, \\ 2, & \text { If the furnace } L_{i j} \text { not selected ladle } k .\end{cases}
$$

3.3. Selection of Ladle Matching Optimization Goals. The firstorder rule learning method [13] is used to learn training set $t$, and the ladle matching attribute set is expressed as $A=$ $\left\{a_{1}, a_{2}, \ldots, a_{18}\right\}=$ steel species, package number,.., empty package weight\}. Variable descriptions are listed in Table 1.

Typical and random data are selected to build the ladle training set, in which the ratio of typical data and random data is $1: 3$, as shown in Table 2. Results of data conversion and the establishment of the relational data are shown in Table 3.

The atomic formula in Table 3 converted from the sample analogy of "ᄀbetter" and "better" is called relational data sample. By using the first-order inductive learner (FOIL) for rule-based learning, the initial empty rule of decarburization ladle matching is

$$
\text { better }(X, Y) \longleftarrow \text {. }
$$

Subsequently, "FOIL Gain" is used for

$$
\text { F_Gain }=\widehat{m}_{+} \times\left(\log _{2} \frac{\widehat{m}_{+}}{\widehat{m}_{+}+\widehat{m}_{-}}-\log _{2} \frac{m_{+}}{m_{+}+\widehat{m}_{-}}\right),
$$

where $\widehat{m}_{+}$and $\widehat{m}_{-}$are the positive and negative examples covered by the new rules after adding candidate words while $m_{+}$and $m_{-}$are the number of positive and negative examples covered by the original rules. On the basis of field expertise, typical positive and negative samples are selected for learning the minimum coverage of all sample attributes corresponding to the optimal target of ladle matching: 
TABLE 1: Definition of ladle matching properties.

\begin{tabular}{lcl}
\hline Attributes & Symbol & Variable description \\
\hline Steel species & $S k$ & Furnace number of the process \\
Package number & $k$ & Ladle serial number \\
Ladle bales regulation & $R_{m}$ & Ladle bales $m$-bit regulation \\
Ladle status & $S_{m}^{k}$ & $m$-bit ladle $k$ state \\
At the end of cold steel volume & $R(k)$ & Ladle $k$ remaining molten steel \\
Ladle temperature & $T(k)$ & The temperature of ladle $k$ \\
Ladle material & $M(k)$ & Ladle $k$ material \\
The number of sewer & $D(k)$ & The number of ladle $k$ 's outlet \\
Usage count & $L(k)$ & The number of ladle $k$ to use \\
Supra number of use (East) & $U_{e}^{k}$ & Ladle $k$ East outlet number of uses \\
The number of use of the outlet (West) & $U_{w}^{k}$ & Ladle $k$ West catchment frequency of use \\
Skate usage (East) & $S_{e}^{k}$ & Ladle $k$ East skateboard use frequency \\
The number of skateboards (West) & $S_{w}^{k}$ & Ladle $k$ West slide use frequency \\
Drainage (East) & $M_{e}^{k}$ & Ladle $k$ drainage material (East) of the material \\
Drainage (West) & $M_{w}^{k}$ & Ladle $k$ drainage material (West) of the material \\
Frame usage (East) & $F_{e}^{k}$ & Ladle $k$ frame (East) use frequency \\
Frame usage (West) & $F_{w}^{k}$ & Ladle $k$ frame (West) number of uses \\
Empty package weight & $E(k)$ & Ladle $k$ empty package weight
\end{tabular}

(1) As-far-as-possible ladle matching high temperature ladle

$$
\max T(k) .
$$

(2) Selected highest number of ladle to be used

$$
\max L(k) .
$$

(3) Preferred low-quality ladle

$$
\max M(k) .
$$

(4) Preferred single ladle

$$
\min D(k) .
$$

3.4. Optional Ladle Constraints. Optional ladle constraints are as follows:

(1) Ladle temperature needs to be within the temperature range required by the process

$$
T_{\min } \leq T(k) \leq T_{\max } .
$$

(2) Number of ladle to be used within process requirements

$$
L_{\min } \leq L(k) \leq L_{\max } .
$$

(3) Ladle material to meet furnace requirements

$$
M_{\min } \leq M(k) \leq M_{\max } .
$$

(4) Number of ladle process to meet the number of ladle requirements

$$
D_{\min } \leq D(k) \leq D_{\max }
$$

(5) Outlet in the furnace within process requirements

$$
U_{\min }^{i j} \leq U(k) \leq U_{\max }^{i j}
$$

(6) Number of ladle skateboards to be used that should be less than the maximum number of uses

$$
\begin{aligned}
S_{e}^{k} & \leq S_{\max }, \\
S_{w}^{k} & \leq S_{\max } .
\end{aligned}
$$

(7) Ladle drainage materials for the material required by the process

$$
\begin{aligned}
& M_{e}^{k}=M_{i j}^{k}, \\
& M_{w}^{k}=M_{i j}^{k} .
\end{aligned}
$$

(8) Ladle frame to be used that should be less than the maximum number of uses

$$
\begin{aligned}
F_{e}^{k} & \leq F_{\max }, \\
F_{w}^{k} & \leq F_{\max } .
\end{aligned}
$$

3.5. Ladle Matching Model Establishment. According to the above analysis, the following ladle matching model is considered:

$$
\begin{array}{cl}
\text { objective: } & (7)-(10), \\
\text { subject: } & (11)-(18) .
\end{array}
$$

The decision variable is $x_{i j}^{k}$. 


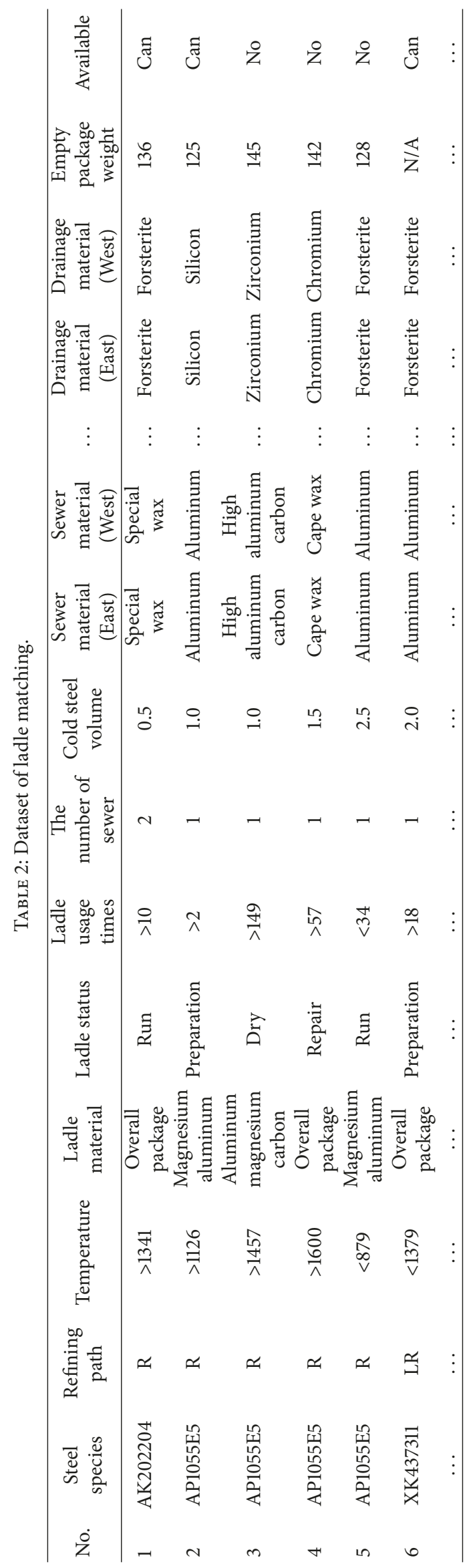


TABLE 3: Data relationship of ladle matching.

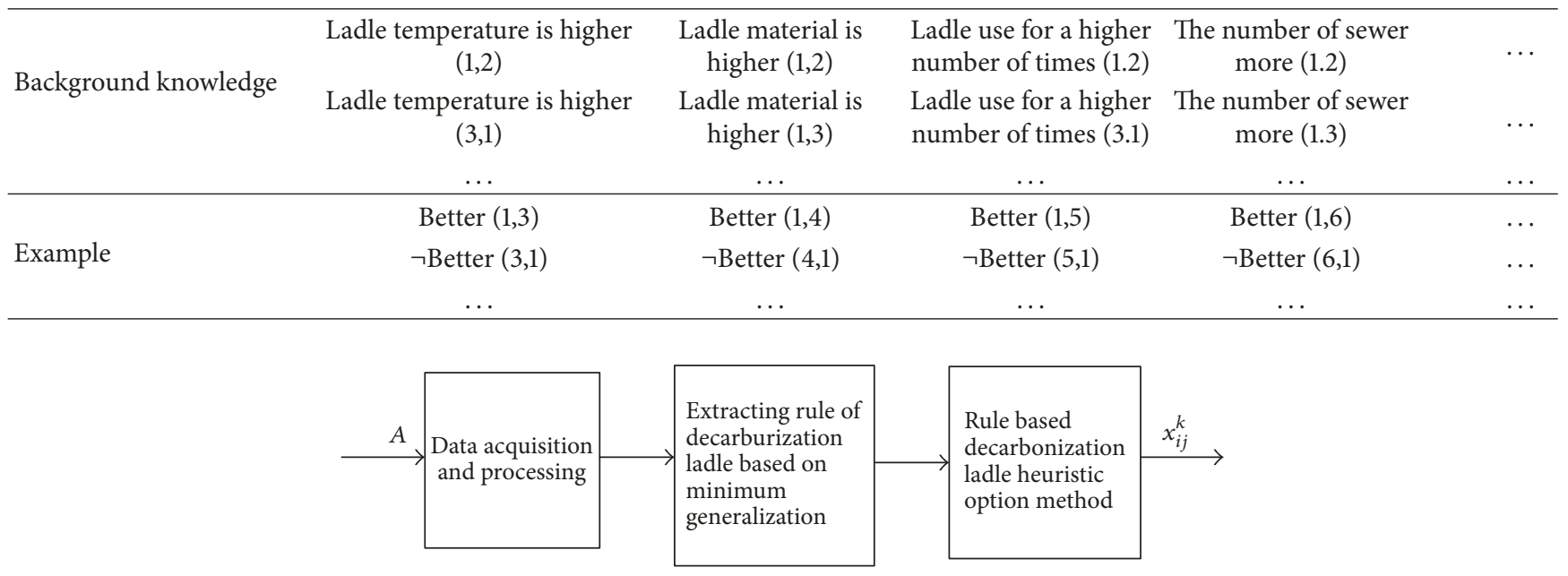

FIGURE 2: Ladle matching method.

\section{Ladle Matching Based on the Learning Rule of Least Generalization}

4.1. Ladle Matching Solution Strategy. The least-generalization method is used to learn the set of decisional rules from decalcified ladle training data, as shown in Figure 2.

\subsection{Ladle Matching Order}

(1) Selection of Converter Completion Time from Morning to Night (Seq1). The extraction requires a matching of optional decarburization furnace times in accordance with the order of completion time of the decarburization converter with a furnace sort set $\Phi=\left\{L_{1}, L_{2}, \ldots, L_{N}\right\}$,

$$
\begin{gathered}
y_{L_{1}, \theta}\left(k_{1}\right) \leq y_{L_{2}, \theta}\left(k_{1}\right), \\
y_{L_{2}, \theta}\left(k_{1}\right) \leq y_{L_{3}, \theta}\left(k_{1}\right), \\
\vdots \\
y_{L_{N-1}, \theta}\left(k_{1}\right) \leq y_{L_{N}, \theta}\left(k_{1}\right),
\end{gathered}
$$

where $N$ is the total number of decarbonized ladle furnaces required, that is, $y_{L_{1}, \theta}\left(k_{1}\right), y_{L_{2}, \theta}\left(k_{1}\right), \ldots, y_{L_{N}, \theta}\left(k_{1}\right)$, for the furnace $L_{1}, L_{2}, \ldots, L_{N}$ decarbonization converter end time.

(2) Selectin of Converter Completion Time from Late to Early (Seq2). The extraction requires a matching of optional decarburization furnace times in accordance with the completion time of decarburization converter with a furnace sort set $\Phi=$ $\left\{L_{1}, L_{2}, \ldots, L_{N^{\prime}}\right\}$,

$$
\begin{gathered}
y_{L_{N^{\prime}-1}, \theta}\left(k_{1}\right) \geq y_{L_{N^{\prime}}, \theta}\left(k_{1}\right), \\
\vdots \\
y_{L_{2}, \theta}\left(k_{1}\right) \geq y_{L_{3}, \theta}\left(k_{1}\right), \\
y_{L_{1}, \theta}\left(k_{1}\right) \geq y_{L_{2}, \theta}\left(k_{1}\right),
\end{gathered}
$$

where $N$ is the total number of decarbonized ladle furnaces that need matching, that is, $y_{L_{1}, \theta}\left(k_{1}\right), y_{L_{2}, \theta}\left(k_{1}\right), \ldots, y_{L_{N}, \theta}\left(k_{1}\right)$, for the furnace $L_{1}, L_{2}, \ldots, L_{N}$ decarburization end time.

\subsection{Ladle Matching Rule Extraction}

4.3.1. Minimal Generalization Rule Learning Method. The least-generalization (LGG) [14] method is used to identify specific facts corresponding to one or more positive examples (initial rules) and to generalize rules to gradually increase sample coverage. The basic idea is as follows:

Get two typical initial rules $r_{1}$ and $r_{2}$ from positive examples as initial formulas. For the given first-order formula $r_{1}$ and $r_{2}$, LGG first finds the text of the same predicate and then examines the constant for each position in the text consecutively. If the constant of two words remains unchanged, the value is recorded as $\operatorname{LGG}(s, t)=V$. Subsequent occurrences of the $\operatorname{LGG}(s, t)$ position with $V$ ignore $r_{1}$ and $r_{2}$ without the text of the common predicate. If the minimum generalization method contains a predicate that is not identified by the formula, then the general generalization method cannot be specialized for that formula. The extraction rule of decarburization ladle matching corresponds to the method for learning A.

The relative minimum generalization (RLGG) [15] defines the initial rule of example $e$ as $e \leftarrow K$, where $K$ is the sum of all atoms in the background. For instance, in accordance with decarburization ladle matching data (Table 2), the initial rules are "available $(1) \leftarrow$ (steel species $=$ AK202204 $) \wedge$ (refining path $=\mathrm{LR}) \wedge \cdots \wedge($ drainage material $($ West $)=$ forsterite $) \wedge$ (empty package weight $=136)$," "available $(6) \leftarrow$ (steel species $=\mathrm{XK} 437311) \wedge($ refining path $=\mathrm{LR}) \wedge \cdots \wedge($ drainage material (West) = forsterite)," and "available $(x) \leftarrow$ (steel species $=$ $Y) \wedge($ refining path $=\mathrm{LR}) \wedge \cdots \wedge($ drainage material (West) = forsterite)." The extraction rule of decarburization ladle matching corresponds to the method for learner B. 


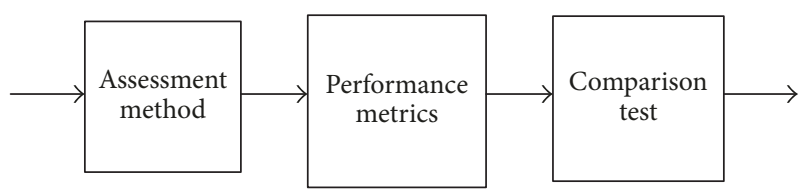

FIGURE 3: Evaluation and selection.

4.3.2. Evaluation and Selection. First, the extraction rules of decarburization ladle learning for the first choice of experimental evaluation methods are assessed and selected. Then, evaluation learners are established for the measurement of generalization standards (i.e., performance metrics). Finally, the performance of learners A and B is conducted. The steps are shown in Figure 3.

(1) Assessment. The extraction rule of decarburization ladle matching is determined to avoid an overfitting or underfitting of training data and learn ladle matching rules as they occur. The end-assessment method [16] is also established. The extraction rule of decarburized ladle selection is used for random division, then the test evaluation is repeated, and the outcome of the assessment results is taken as the average. Two-thirds of the data samples are selected for rule extraction training whereas the remaining one-third of the data samples are used to evaluate the test error.

(2) Performance Metrics. In the extraction rule of decalcification ladle matching, error rate is defined as the number of misclassifications of the total sample size ratio. Thus, accuracy depicts the correct number of samples classified by the proportion of the total sample. The sample decimation rules for decarburization ladle extraction set $D$ are extracted. Classification error rate is defined as

$$
E(f ; D)=\frac{1}{m} \sum_{i=1}^{m} \operatorname{II}\left(f\left(x_{i}\right) \neq y_{i}\right)
$$

For the sample including two types of misclassified samples and correctly classified samples, accuracy is defined as

$$
\operatorname{acc}(f ; D)=\frac{1}{m} \sum_{i=1}^{m} \operatorname{II}\left(f\left(x_{i}\right)=y_{i}\right)=1-E(f ; D),
$$

where $\operatorname{II}(\bullet)$ is the indicator function: if $\bullet$ is true, the value is 1 ; otherwise the value is 0 . According to the parameters in Table 1 , determine the comparison results of $f\left(x_{i}\right)$ and $y_{i}$.

Ladle matching is grouped into two classifications (i.e., real category and learner prediction category). Subsequently, ladle matching test samples are subclassified as real cases, false positive cases, true negative cases, and false negative cases. The forecast results TP, FP, TN, and FN represent a corresponding sample number. Hence, $\mathrm{TP}+\mathrm{FP}+\mathrm{TN}+\mathrm{FN}=$ total number of samples. The full "confusion matrix" of the classification results extracted by the decarburization ladle matching rule is shown in Table 4 .
TABLE 4: Classification result of confusion matrix.

\begin{tabular}{lcc}
\hline \multirow{2}{*}{ True situation } & \multicolumn{2}{c}{ Forecast result } \\
& Positive example & Counter example \\
\hline Positive example & TP & FN \\
Counter example & FP & TN \\
\hline
\end{tabular}

TABLE 5: Contingency table of learner classification differences.

\begin{tabular}{lcc}
\hline Algorithm B & \multicolumn{3}{c}{ Algorithm A } \\
& True & False \\
\hline True & $e_{00}$ & $e_{01}$ \\
False & $e_{10}$ & $e_{11}$ \\
\hline
\end{tabular}

Accuracy rate $P$ and recall rate $R$ are expressed as

$$
\begin{aligned}
& P=\frac{\mathrm{TP}}{\mathrm{TP}+\mathrm{FP}}, \\
& R=\frac{\mathrm{TP}}{\mathrm{TP}+\mathrm{FN}} .
\end{aligned}
$$

Samples are sorted according to the learner prediction of ladle selection, that is, as prescribed by rules which learners consider "most likely" to be positive followed by rules considered "least likely" to be positive. Homeopathic rules are selected consecutively as a positive example for prediction, then the current recall and accuracy rates are calculated. The BEP (Break-Even Point) [17] is also defined for "rate of recall $=$ recall rate value." The advantages and disadvantages of learners A and B can be compared based on BEP. Finally, LGG and RLGG are measured on the basis of BEP and expressed as follows:

$$
F_{\beta}=\frac{\left(1+\beta^{2}\right) \times P \times R}{\left(\beta^{2} \times P\right)+R} .
$$

If accuracy and recall rates are equally important, then a high recall rate corresponds to a high accuracy rate. Precision is the most important aspect of decarbonization ladle matching when aiming for safety of production. Thus, the highest LGG and RLGG values are considered to identify the error rate to meet accuracy and precision requirements.

(3) Comparison Test. The set aside method for ladle matching based on two-classification problems not only estimates the test error rates of learners $\mathrm{A}$ and $\mathrm{B}$, but also obtains the difference between the results of LGG and RLGG. Table 5 shows the result options (i.e., both correct, both wrong, and one is correct whereas the other is wrong) of the difference.

If LGG and RLGG behave identically, then $e_{01}=e_{10}$. Thus, $\left|e_{01}-e_{10}\right|$ obeys the normal distribution in which mean is 1 and variance is $e_{01}+e_{10}$.

$$
\tau_{\chi^{2}}=\frac{\left(\left|e_{01}-e_{10}\right|-1\right)^{2}}{e_{01}+e_{10}} .
$$

The $\chi^{2}$ distribution with 1 degree of freedom is observed. If the variable value is less than the threshold value 
TABLE 6: $\tau_{\chi^{2}}$ value of learner.

\begin{tabular}{ccccccc}
\hline \multirow{2}{\tau}{$\tau_{\chi^{2}}$} & 120 & 240 & 360 & 600 & 1200 & 2400 \\
\hline $\mathrm{A}$ & 3.5310 & 4.4395 & 4.8323 & 4.1035 & 5.3536 & 5.3604 \\
$\mathrm{~B}$ & 3.2132 & 3.8531 & 4.1965 & 3.8542 & 5.1303 & 5.1743 \\
\hline
\end{tabular}

$\left(\chi_{\alpha}^{2}=3.8415 ; \alpha=0.05\right)$, then the assumption that no difference exists between LGG and RLGG performance is correct; otherwise, the assumption is rejected. A low average error rate for learner performance is problematic. The rules extracted for decarburization ladle matching using different learning and test data are shown in Table 6.

The extraction rules for ladle selection involve additional test data in order for the learner learning results to gradually overcome underfitting or overfitting. Results showed that learner B performed better than learner A. The RLGG for optional decarburization ladle using this method can also efficiently obtain the matching rules.

4.3.3. Ladle Selection Rules. The ladle matching rules extracted from field data are as follows.

Rule 1 (the steel is a steel cord). The steel grades are steel cord types (i.e., beginning with $K K$ or $X K$ ). Ladle packages of less than 50 and number of sinks greater than or equal to 2 and less than 10 are selected.

$$
\begin{array}{cl}
\text { IF } & S k_{1,2}=K K, \\
& \text { or } S k_{1,2}=X K, \\
\text { THEN } \quad L(k)<50, \\
\\
2 \leq \frac{U_{e}^{k}}{U_{w}^{k}}<10 .
\end{array}
$$

Rule 2 (the furnace contains LF refining). The number of water used is not more than 15 and packet ladle is less than 100.

$$
\begin{array}{cl}
\text { IF } & l f \text { in } F \\
\text { THEN } & U_{e}^{k} \leq 15, \\
& U_{w}^{k} \leq 15, \\
& L(k)<100 .
\end{array}
$$

Rule 3. The furnace is the first furnace used for continuous casting. The first furnace cannot use the new continuous casting package.

$$
\begin{array}{cl}
\text { IF } & j=1, \\
\text { THEN } & L_{i 1}(k) \neq 0 .
\end{array}
$$

Rule 4. The material is divided into three $(M(k)=$ 5 or 6 or 7 ). The first bale regulation $R_{1}$ is set as the minimum requirement for the ladle material.

$$
\text { IF } R_{1}=0 \text { or } 5 \text {, }
$$

THEN $M(k)=5$ or 6 or 7 ,

$$
\begin{aligned}
\text { IF } & R_{1}=6, \\
\text { THEN } & M(k)=6 \text { or } 7, \\
\text { IF } & R_{1}=7, \\
\text { THEN } & M(k)=7 .
\end{aligned}
$$

Rule 5 (the steel meets the new package or cold pack restrictions). The second big bag regulation $R_{2}$ meets the new bag and cold bag requirements. If $R_{2}=0$, then "No rules"; if $B=1$, then "Disable the new package."

$$
\begin{array}{cl}
\text { IF } & R_{2}=1, \\
\text { THEN } & L(k) \neq 0 .
\end{array}
$$

If $R_{2} \geq 2$, then the new package and cold package are disabled. The same ladle is selected as the second package following the ladle status code.

$$
\begin{array}{cl}
\text { IF } & R_{2} \geq 2, \\
\text { THEN } & L(k) \neq 0, \\
& R_{2}=S_{2}^{k} .
\end{array}
$$

Rule 6. The ladle meets furnace restrictions. The third bit of bale regulation is $C=0$, which means that the previous furnace has no requirements; otherwise, the ladle with the same status as the big bale code is selected.

$$
\begin{aligned}
\text { IF } & R_{3} \neq 0, \\
\text { THEN } & R_{3}=S_{3}^{k} .
\end{aligned}
$$

The set of available ladles removes nonconforming ladles by rules 1-6, and the final number of ladles uses the RP-based selection for ladle matching.

Rule 7 (optional priority).

Priority 1 (ladle material rules). Priority choice of low-quality ladle

$$
k=\arg \min M(k)
$$

Priority 2 (ladle rules). Preferred ladle with relatively fewer nozzles

$$
k=\arg \min D\left(k_{l}\right)
$$

Priority 3 (highest temperature rule). Preferred temperature for ladle matching

$$
k=\arg \max T\left(k_{l}\right) .
$$


Priority 4 (highest usage rule). Preferred use of the number of ladles

$$
k=\arg \max L\left(k_{l}\right) .
$$

Priority 5 (random rules). Random selection of ladles

$$
k=\arg \text { random }\left\{k_{l}\right\} .
$$

The weight coefficients of the five $\langle M(k), D(k), T(k)$, $L(k), k\rangle$ are $\alpha, \beta, \chi, \gamma$, and $\delta$. In this order, the optional weight coefficient is $W_{i}$ :

$$
\begin{aligned}
W_{i}= & \alpha \cdot\langle M(k)\rangle+\beta \cdot\langle D(k)\rangle+\chi \cdot\langle T(k)\rangle+\gamma \\
& \cdot\langle L(k)\rangle+\delta \cdot\langle k\rangle .
\end{aligned}
$$

The parameters $\alpha, \beta, \chi, \gamma$, and $\delta$ are based on their priorities. In different combinations, there are different priorities. Based on experience, ensure that the low priority parameters do not affect the high priority parameters.

4.4. Optional Ladle Heuristic Algorithm. The rule-priority ladle matching method is established, and the priority combinations are shown in Table 7.

Step 1. Ladle assembly $\Omega$ composed of all ladles is constructed. Then, ladle state $S$ (i.e., see Table 1 for parameters) is initialized, and heatsink set $\Phi$ for ladle matching is constructed. By referring to the master production and scheduling plan, which shows the matching ladle furnace requirements and converter completion time sorting, the furnace is set to $\Phi=\left\{L_{1}, L_{2}, \ldots, L_{N}\right\}$. Subsequently, $n=1$ is initialized.

Step 2. The status of all ladles is updated.

Step 3. Furnace $L_{n}, n=1,2, \ldots, N$, is established according to (11)-(18). All ladles that do not meet requirements, and available ladles are updated as $\Omega$.

Step 4. According to (25)-(31), $\Omega$ is rejected if ladle requirements are not met.

Step 5. If $|\Omega|>1$, then the most suitable ladle on the basis of the RP method is selected. Subsequently, $x_{i j}^{k}$ is determined. If $n=N$, then proceed to Step 6 . If $n=n+1$, then proceed to Step 2 .

Step 6. End.

The furnace ladle matching process is shown in Figure 4.

\section{Simulation Experiment}

5.1. Simulation Experiment Design. Different methods for heuristic decarburization ladle matching are established on the basis of ladle selection and matching priorities and combinations (Table 8).

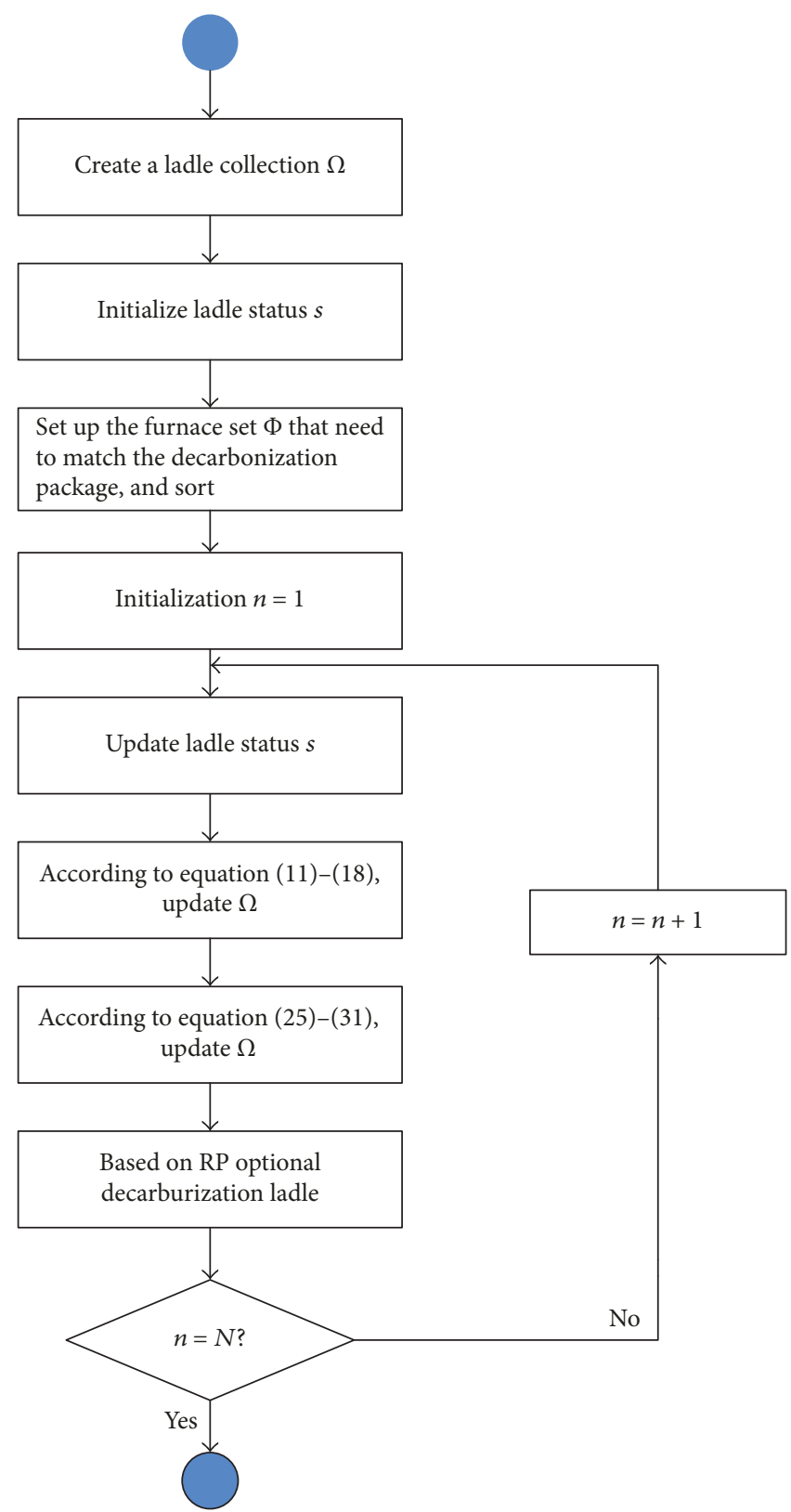

FIGURE 4: Functional flow diagram of ladle matching.

The options for furnace decarbonization include Seq1 and Seq2, as explained in Section 4.2. The ladle matching rules include 24 priority levels, as shown in Table 7. According to the priority, the values of parameters are 50000, 5000, 500, 50 , and 1.

Planners are required to seek the optimal combination of production work orders to minimize cost and improve efficiency based on these attributes [18]. The evaluation program [19] uses the fuzzy comprehensive evaluation-weighted average composite model. The set of evaluation factors is evaluated, and the evaluation value of the matching results is calculated, as shown in Figure 5.

The simulation parameters are described as follows: 


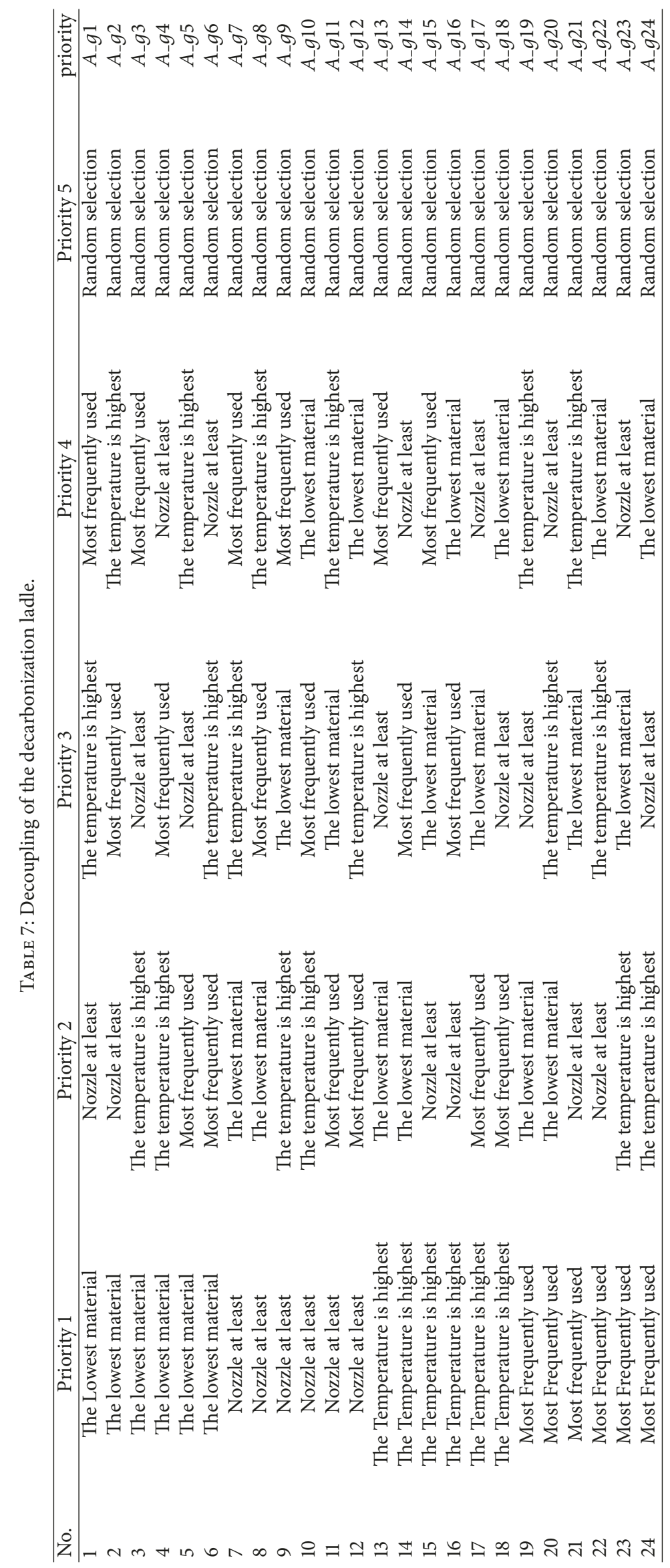




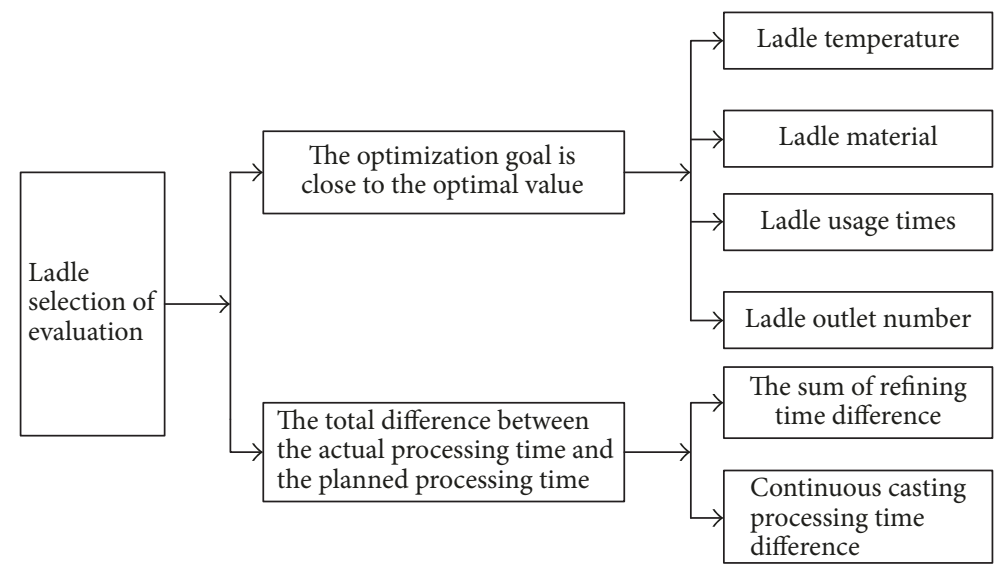

FIgURE 5: Functional evaluation flow diagram.

TABLE 8: Decoupling of the decarbonization ladle.

\begin{tabular}{lccc}
\hline No. & Sort & Priority & Matching method \\
\hline 1 & Seq1 & $A_{g 1}$ & $H_{1}$ \\
$\ldots$ & $\ldots$ & $\ldots$ & $\ldots$ \\
24 & Seq1 & $A_{g 24}$ & $H_{24}$ \\
25 & Seq2 & $A_{g 1}$ & $H_{25}$ \\
$\ldots$ & $\ldots$ & $\ldots$ & $\ldots$ \\
48 & Seq2 & $A_{g 24}$ & $H_{48}$ \\
\hline
\end{tabular}

(1) Number of furnace scale $C_{1}$ refers to the number of heats that need an optional ladle. $C_{1}=1$ denotes small-scale furnace with number of heats $N \in[0,30]$, $C_{1}=2$ denotes medium-size furnace time with $N \in$ $[31,90]$, and $C_{1}=3$ denotes large-scale heat with $N \in[91,200]$.

(2) Ladle initial parameter $C_{2}$ refers to the initial parameters of the generation method. As shown in Table 1, $C_{2}=1$ denotes each ladle property by which the random selection process obtains the upper or lower limit value; $C_{2}=2$ corresponds to the process of the upper limit or lower limit $\pm 10 \%$ (random value); and $C_{2}=3$ corresponds to upper limit or lower limit allowance of $\pm 10 \%$, which obeys normal distribution.

(3) Ladle turnover scale $C_{3}$ refers to the number of ladles representing onsite turnover. $C_{3}=1$ represents smallscale turnover with $K \in[9,13] ; C_{3}=2$ represents medium-sized turnover with $K \in[14,21]$; and $C_{3}=3$ represents large-scale turnover with $K \in[22,35]$.

5.2. Simulation Results. The number of each type of furnace scale (1-3) is a selection problem for three datasets corresponding to comprehensive evaluation results (Table 9). Method $H_{1}$ performs better than the other methods. As the scale of furnace size $C_{1}$ increases, the degrees of performance of various heuristic methods gradually decrease. Ladle performance declines with the increase of furnace scale, and the number of ladles that furnace requires also decrease. The performance of the heuristic method for the initial parameters of ladle $C_{2}=3$ is slightly better compared with the other ladles. As the number of onsite ladle turnover increased, the performance of the heuristic method gradually increased because more ladles are selected at the furnace. However, the difference between $C_{3}=2$ and $C_{3}=3$ is not significant because the cost of manufacturing and maintenance is very high. Lower ladle turnover is the ideal setup, and using a mid-size ladle is recommended.

5.3. Parameter Analysis. The scheduling effect of heuristic method $H_{1}$ on the evaluation value is analyzed when parameters $C_{1}, C_{2}$, and $C_{3}$ are changed. When parameter $C_{1}$ increased (i.e., better high furnace scale), $H_{1}$ performance continuously worsened. When the value of parameter $C_{2}$ changed (i.e., more ladles with better performance), $H_{1}$ performance continuously improved. When parameter $C_{1}$ increased (i.e., better furnace scale), $H_{1}$ performance continuously worsened. When the value of parameter $C_{3}$ changed (i.e., higher ladle turnover), $H_{1}$ performance improved. When parameter $C_{2}$ changed (i.e., more ladles with better performance), $H_{1}$ performance continuously worsened. When parameter $C_{3}$ increased (i.e., higher ladle turnover), $H_{1}$ performance continuously improved.

\section{Industrial Applications}

Heuristic method $H_{1}$ is identified in this study as the best optional ladle treatment. This method can be applied to the steelmaking-continuous casting scheduling system of large iron and steel enterprises in Shanghai. A number of such large-scale enterprises typically involve three converters, seven refining furnaces, and three continuous casting machines. A sample ladle matching interface is shown in Figure 6.

The ladle matching program proposed in this study is compared with the manually handled onsite ladle scheduling. The average time to prepare a ladle matching program using the proposed method is 3.4 seconds lower than the average preparation time of 30 seconds; the number of online ladles is reduced from 23 to 19; and the number of ladle maintenance 


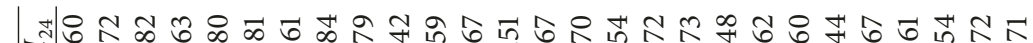

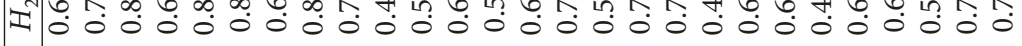

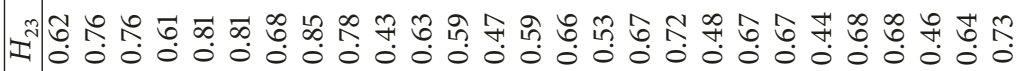

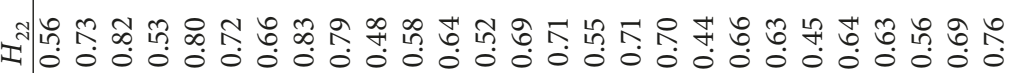
갠의

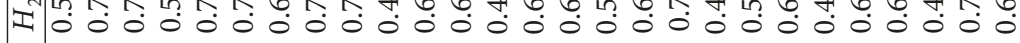

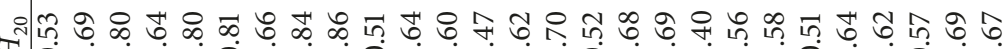

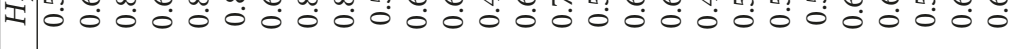

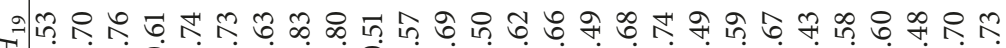

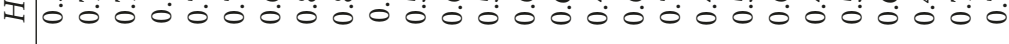
舟绍只

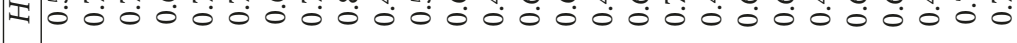

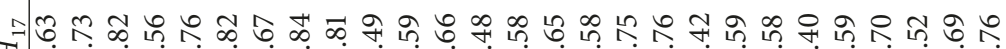

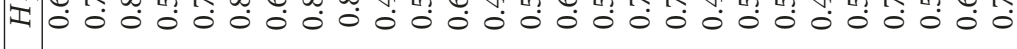

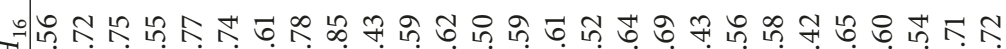
I

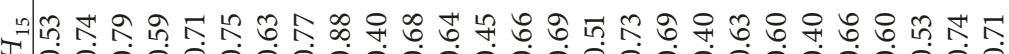

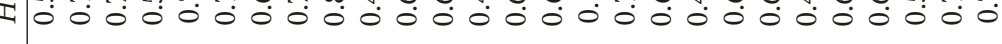

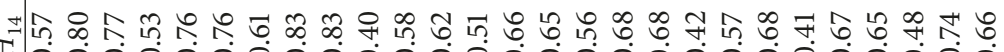

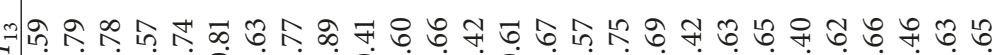

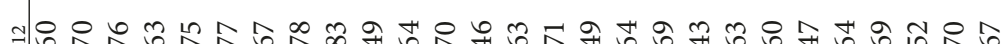

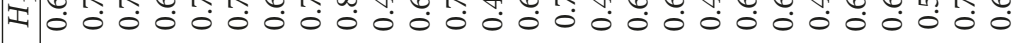
$=$ =

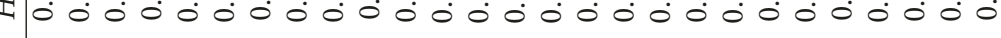

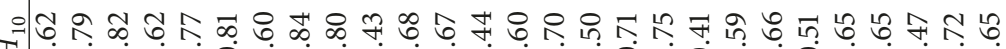
I

in

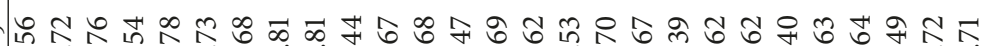

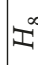

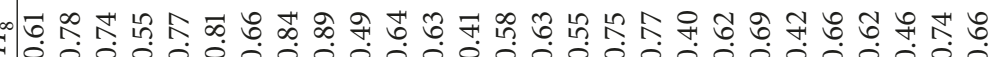

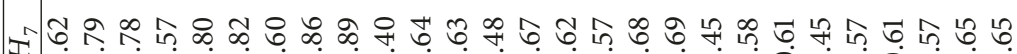

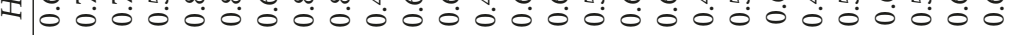

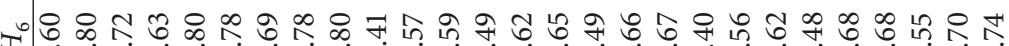
工

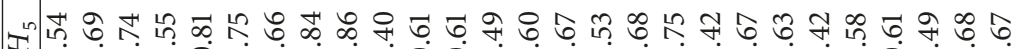

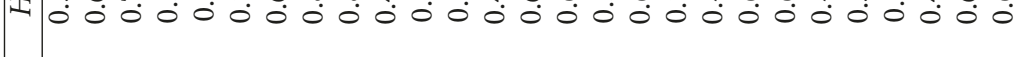

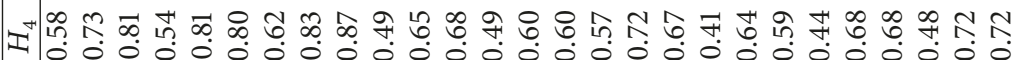

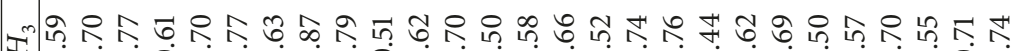

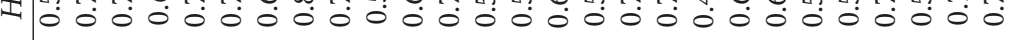

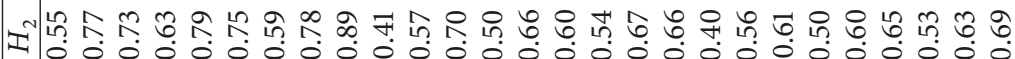
=

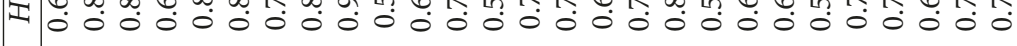
0 $\dot{\dot{z}}$ $\mid$

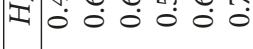

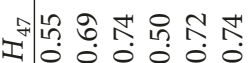
$\pi \mid \begin{array}{llllll}0 & 0 & 0 & 0 & 0 & 0\end{array}$

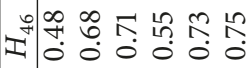

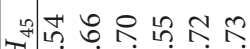

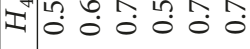

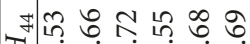

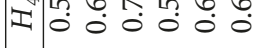

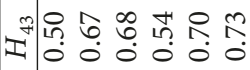

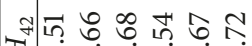
$\pi \mid 00000$

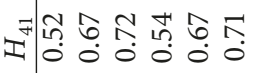

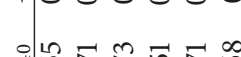

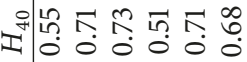
象喵 $I_{1}=0$ min

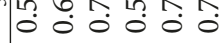

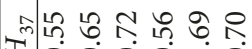
웅 00

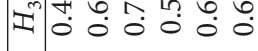

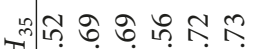

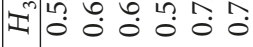

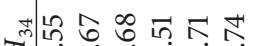
I 1 ?

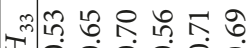
I la c: 0

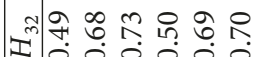
I 00000

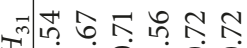

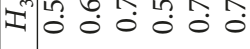

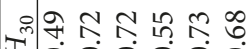

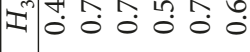

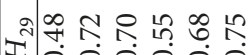

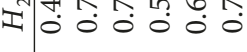

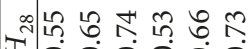

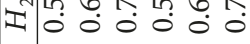
눠 A

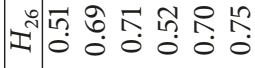

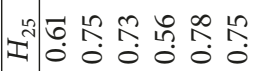

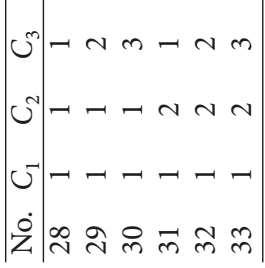




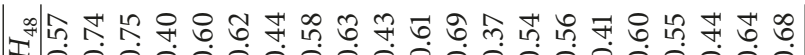
工 000000000000

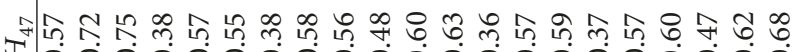
I 0 o 00000000000000000000

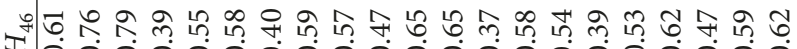
I 000000000000000

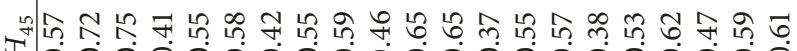
4000000000000000000000

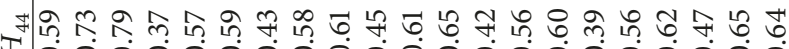

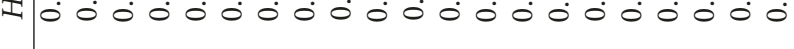

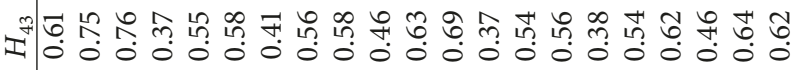

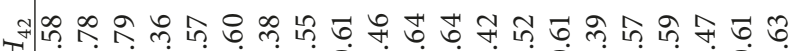

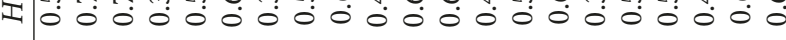

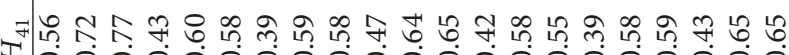
I 0000000000000000000

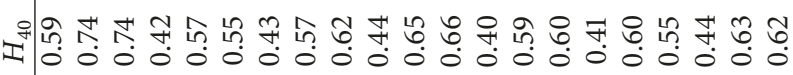

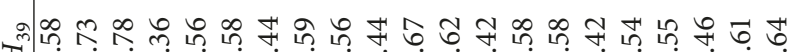

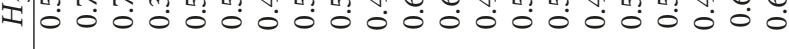

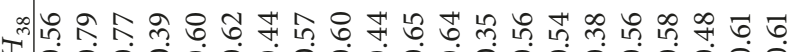

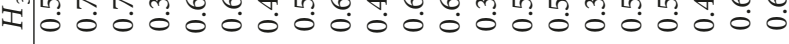

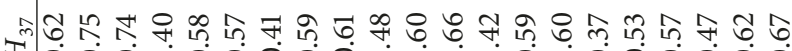

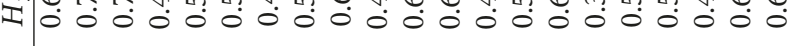
承径

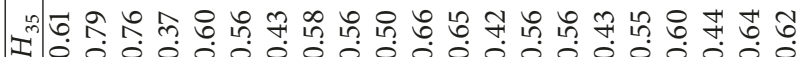

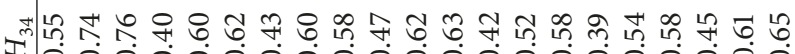

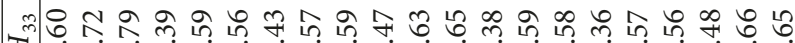

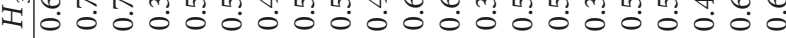
ఇ⿹丁口⿹

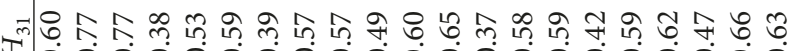

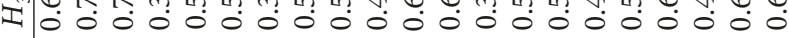

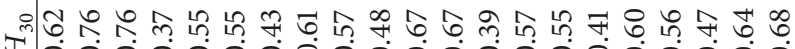

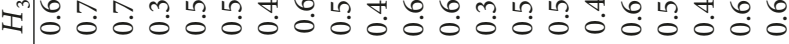

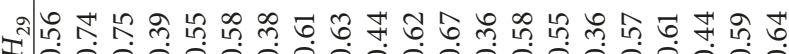

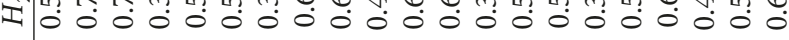

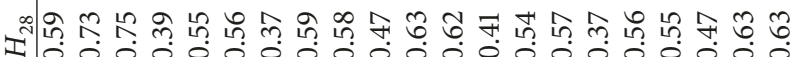

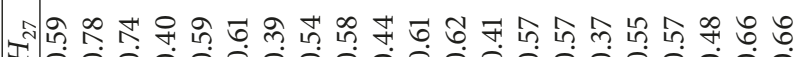

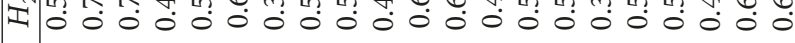

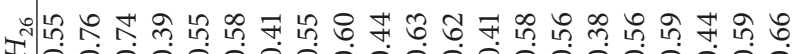

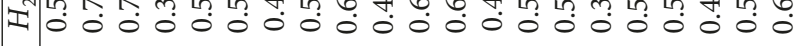

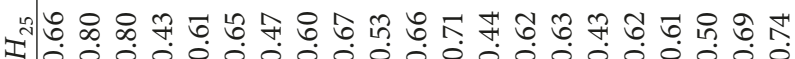
ن

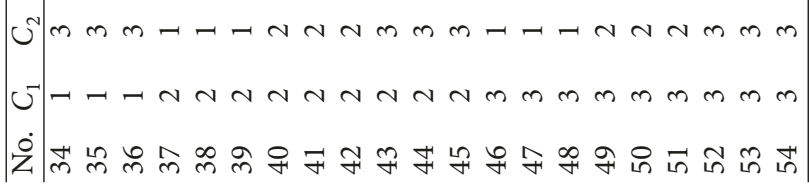




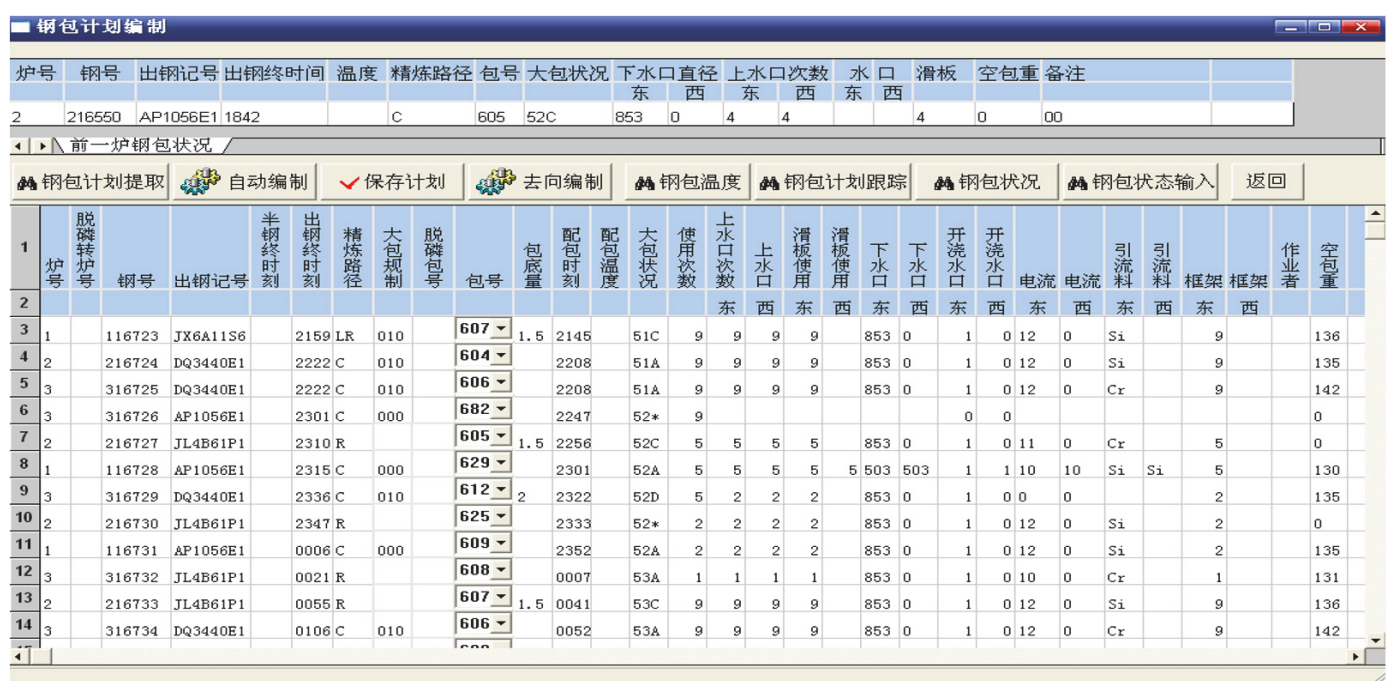

FIgURE 6: The interface display of ladle matching.

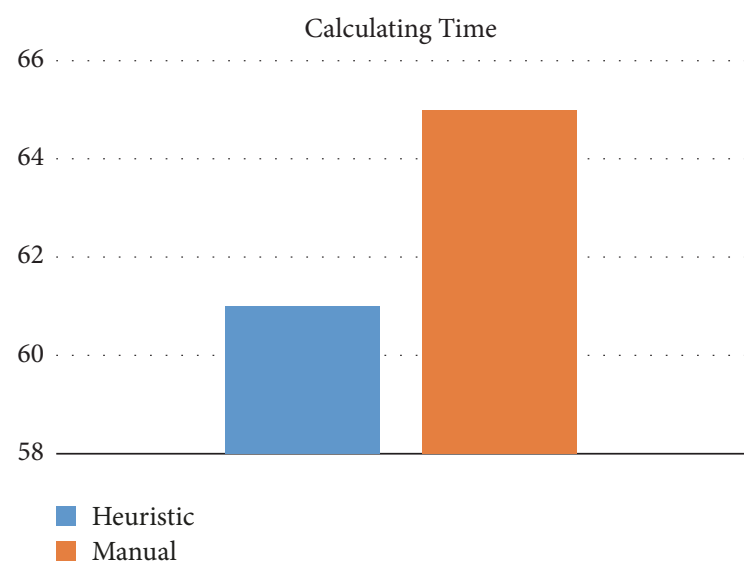

Maintenance Number

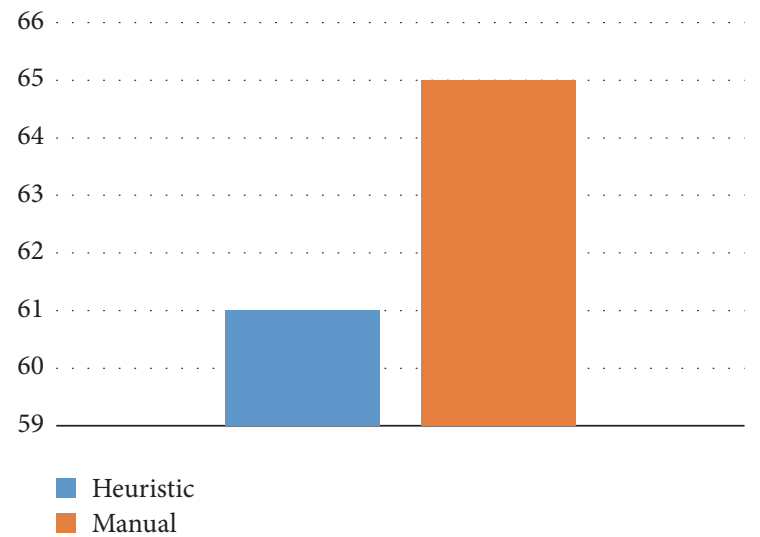

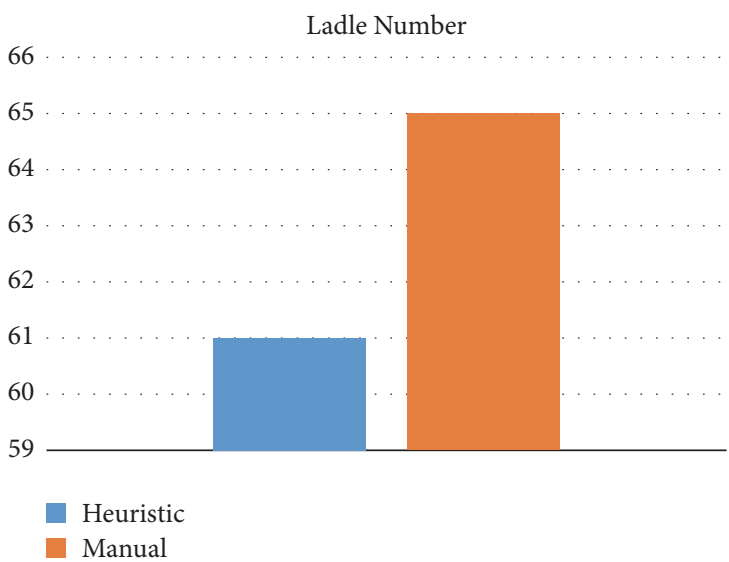

Time Hit Rate (\%)

66

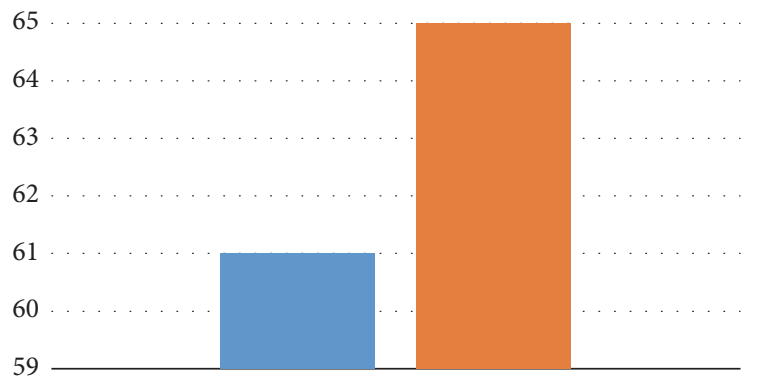

Heuristic

Manual

FIgURE 7: Comparison of application indicators.

times is reduced from 17 to 12 . Compared with that of manual preparation, the time hit rate of the heats (i.e., proportion of furnaces processed at a specific start time defined by a planned time point) of the proposed method increased from $61 \%$ to $65 \%$ (Figure 7 ). Thus, adopting the method in this study may lead to smoother ladle turnover and better economic efficiency of large-scale enterprises compared with those of conventional methods. 


\section{Conclusion}

The current method of ladle scheduling is inefficient, and resource wastage caused by manual ladle matching can easily lead to redundant production times during steelmaking-continuous casting. The first-order rule learning method is used to extract key attributes, such as highest ladle temperature, longest ladle life, lowest-level ladle material, and ladle outlet for the minimum values of the performance indicators. Then, the optional decarburization ladle model is established. Based on the actual data of a large iron and steel enterprise in Shanghai, a method for decarburized ladle selection is determined on the basis of rule learning. The proposed ladle matching method can meet ladle process requirements and minimize inefficient production as a result of unreasonable choice of ladle delays. Compared with the manual preparation of onsite dispatching staff, the proposed model offers smoother ladle turnover and better production efficiency. Consequently, the optional decarburization ladle process for steelmaking-continuous casting production scheduling can improve the economic efficiency of large-scale enterprises.

\section{Conflicts of Interest}

The authors declare that they have no conflicts of interest.

\section{Acknowledgments}

This work was supported in part by National Natural Science Foundation of China (61773269, 61603262, and 61503259), Science and Technology Fund of Shenyang (17-231-1-75), China Postdoctoral Science Foundation Funded Project (2017M611261), SJZU Postdoctoral Innovation Fund Project (SJZUBSH201705), Chinese Scholarship Council, and Hanyu Plan of Shenyang Jianzhu University.

\section{References}

[1] J.-Q. Li, Q.-K. Pan, and K. Mao, "A hybrid fruit fly optimization algorithm for the realistic hybrid flowshop rescheduling problem in steelmaking systems," IEEE Transactions on Automation Science and Engineering, vol. 13, no. 2, pp. 932-949, 2016.

[2] B. Huang, N. Tian, Z. Shi, Z. Ma, and X. Zhou, "Precondition and influence factors of steel ladle interaction," Journal of Chongqing University, vol. 40, no. 2, pp. 52-59, 2017.

[3] L.-L. Sun and X.-Y. Wang, "Application of mix optimization scheduling approach for steelmaking-continuous casting process based on actual steelmaking industry," International Journal of Iron and Steel Research, vol. 20, no. 10, pp. 1-9, 2013.

[4] M. P. Fanti, G. Rotunno, G. Stecco, W. Ukovich, and S. Mininel, "An Integrated System for Production Scheduling in Steelmaking and Casting Plants," IEEE Transactions on Automation Science and Engineering, vol. 13, no. 2, pp. 1112-1128, 2016.

[5] T. Zhang and O. Rose, "Scheduling in a flexible job shop with continuous operations at the last stage," Journal of Simulation, vol. 10, no. 2, pp. 80-88, 2016.

[6] B.-F. Huang, Z. Shi, G.-F. Zhang, and X.-L. Zhou, "Saving ladle control model of steel ladle in steelworks," Advanced Materials Research, vol. 1015, pp. 700-707, 2014.
[7] I. Shukla, G. Rajesh, P. Agarwal, A. K. Shukla, and D. Philip, "Lean operations strategy to combat uncertainties in temperture at bof end point, tapping, deoxidation, alloy addition and thermal history," in Celebrating the Megascale, pp. 333-339, Springer International Publishing, 2014.

[8] K. Feng, D. He, A. Xu et al., "Study on the evaluation method of ladle scheduling," Journal of Northeastern University (Natural Science), vol. 36, no. 12, pp. 1728-1732, 2015.

[9] B. Wang, B. Wang, Y. Q. Mu, Q. Liu, and X. C. Lu, "Optimization and control of ladle operation for special steel plants," Applied Mechanics and Materials, vol. 602-605, pp. 899-902, 2014.

[10] P. Duan, J. Li, Y. Wang, H. Sang, and B. Jia, "Solving chiller loading optimization problems using an improved teachinglearning-based optimization algorithm," Optimal Control Applications \& Methods, vol. 39, no. 1, pp. 65-77, 2018.

[11] Y. Tan, Z. Wei, S. Wang et al., "Optimization algorithm for ladle scheduling based on the BRPTW-AT mode," Journal of Systems Engineering, vol. 1, pp. 94-100, 2013.

[12] Z. Wei, T. Zhu, T. He, and S. Liu, "A fast heuristic algorithm for ladle scheduling based on vehicle routing problem with time windows model," ISIJ International, vol. 54, no. 11, pp. 25882597, 2014.

[13] Z. Zhihua, Machine Learning, Tsinghua University Press, Beijing, China, 2016.

[14] S. Lapointe and S. Matwin, "A tool for efficient induction of recursive programs," in Proceedings of the Eleventh International Conference, pp. 273-280, 2014.

[15] W. Alsanie and J. Cussens, "Learning a generative failure-free PRISM clause," Latest Advances in Inductive Logic Programming, pp. 87-93, 2014.

[16] F. Schroff, D. Kalenichenko, and J. Philbin, "FaceNet: a unified embedding for face recognition and clustering," in Proceedings of the IEEE Conference on Computer Vision and Pattern Recognition (CVPR '15), pp. 815-823, IEEE, Boston, MA, USA, June 2015.

[17] A. Nonis, B. De Nardi, and A. Nonis, "Choosing between RTqPCR and RNA-seq: a back-of-the-envelope estimate towards the definition of the break-even-point," Analytical and Bioanalytical Chemistry, vol. 406, no. 15, pp. 3533-3536, 2014.

[18] Y. Liu, Q.-K. Pan, and T. Chai, "Magnetic material group furnace problem modeling and the specialization of the genetic algorithm," IEEE Transactions on Engineering Management, vol. 62, no. 1, pp. 51-64, 2015.

[19] X. Deng, Y. Hu, Y. Deng, and S. Mahadevan, "Supplier selection using AHP methodology extended by D numbers," Expert Systems with Applications, vol. 41, no. 1, pp. 156-167, 2014. 


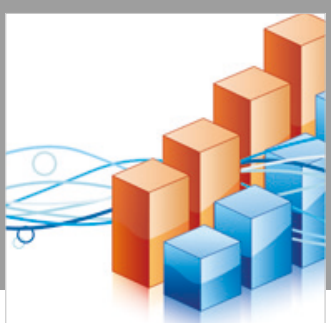

Advances in

Operations Research

\section{-n-m}
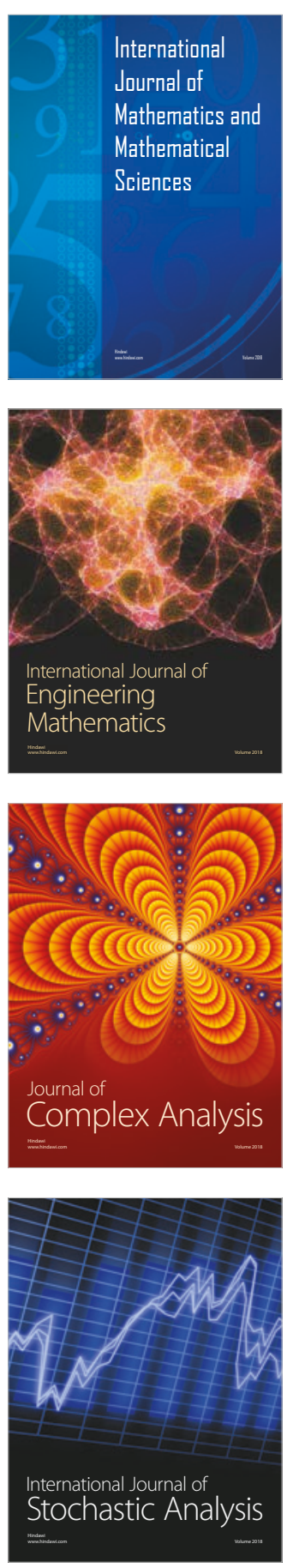
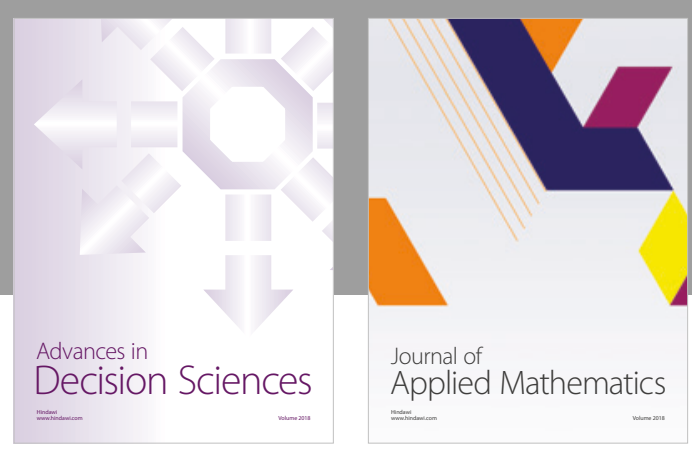

Journal of

Applied Mathematics
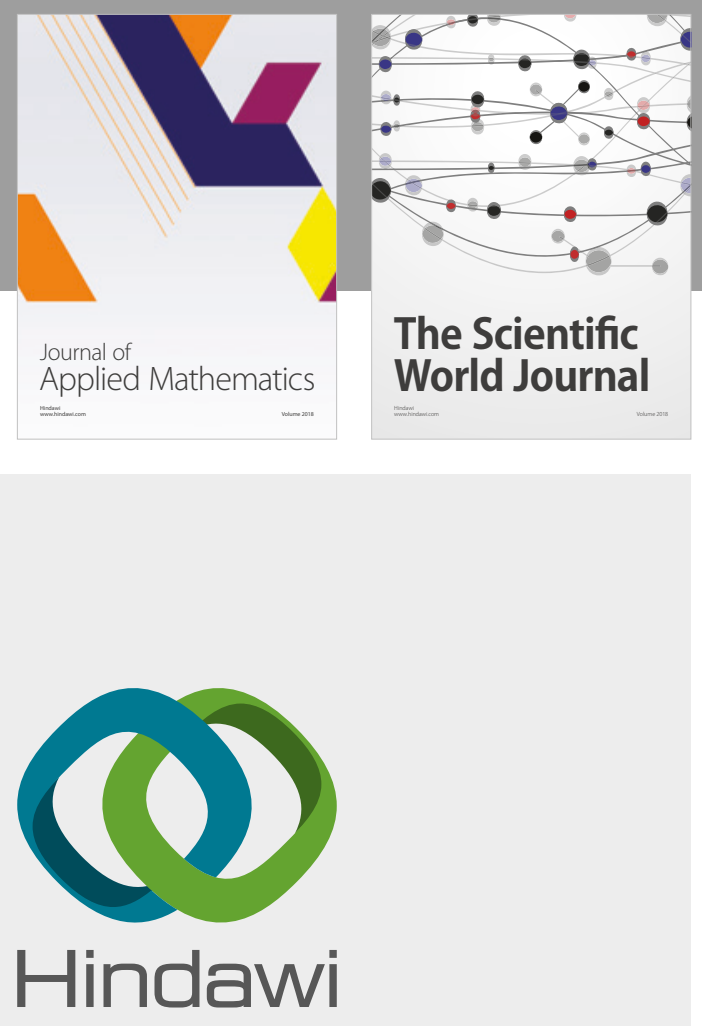

Submit your manuscripts at

www.hindawi.com

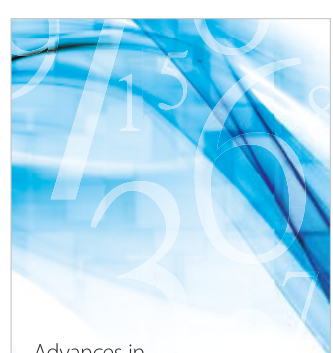

Advances in
Numerical Analysis
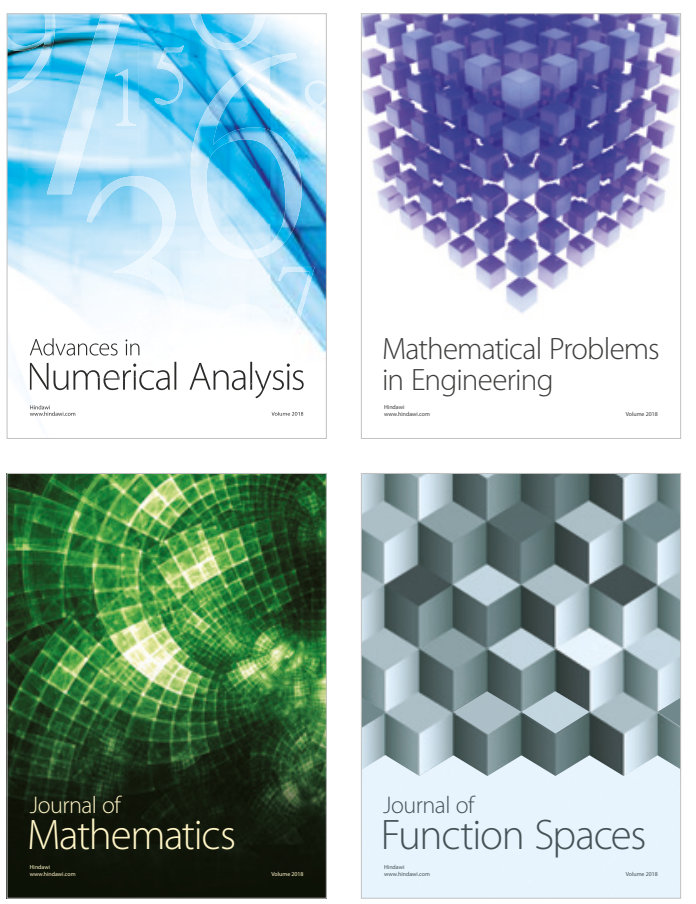

Mathematical Problems in Engineering

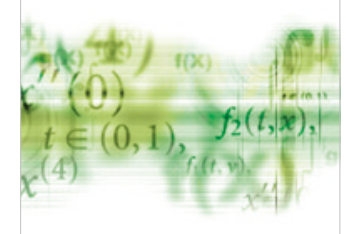

International Journal of

Differential Equations

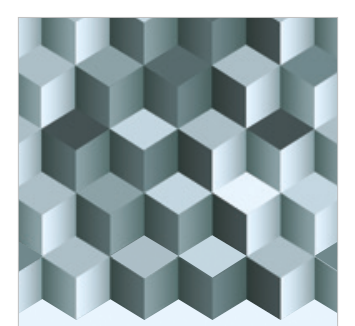

Journal of

Function Spaces

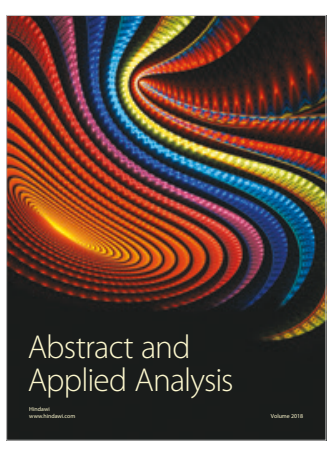

The Scientific

World Journal

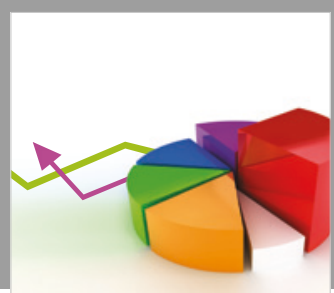

Journal of

Probability and Statistics
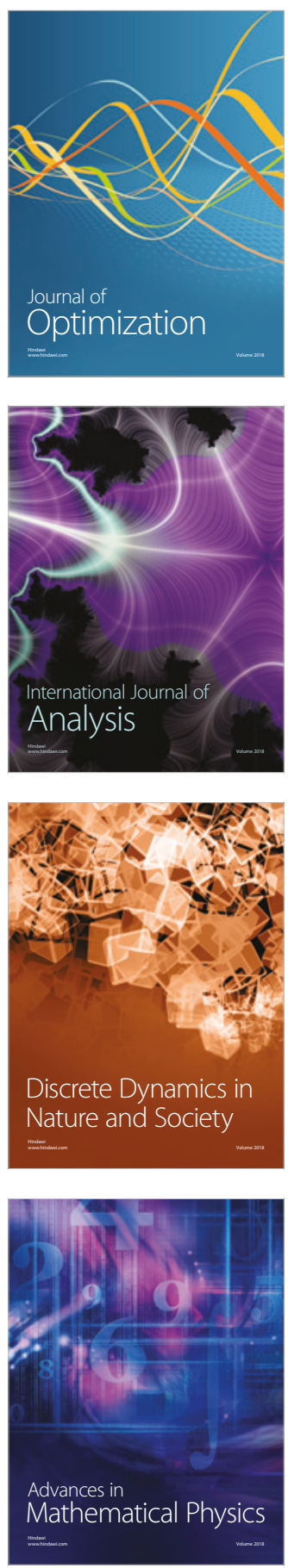